\title{
Mirodenafil Prevents Bladder Dysfunction Induced by Chronic Bladder Ischemia in Rats
}

\author{
Hoon Choi ${ }^{1}$, Jae Hyun Bae ${ }^{1}$, Ji Sung Shim¹리 Jae Young Park ${ }^{1}$, Du Geon Moon², Jeong Gu Lee \\ ${ }^{1}$ Department of Urology, Korea University Ansan Hospital, Korea University College of Medicine, Ansan, Korea \\ ${ }^{2}$ Department of Urology, Korea University Guro Hospital, Korea University College of Medicine, Seoul, Korea \\ ${ }^{3}$ Department of Urology, Korea University Anam Hospital, Korea University College of Medicine, Seoul, Korea
}

Purpose: To investigate the protective effect of mirodenafil on bladder function in a rat model of chronic bladder ischemia (CBI).

Methods: Twenty-four Sprague-Dawley rats were randomized to three groups: untreated, sham-operated rats (control group); untreated, CBI model rats (CBI group); and CBI rats treated daily with $4 \mathrm{mg} / \mathrm{kg}$ mirodenafil (CBI + mirodenafil group). The $\mathrm{CBI}$ and $\mathrm{CBI}+$ mirodenafil groups underwent endothelial injury to the iliac arteries and were fed a $2 \%$ cholesterol diet after injury. Four weeks after surgery, the CBI + mirodenafil group started daily treatment with mirodenafil for four weeks. Eight weeks after surgery, continuous in vivo cystometry and in vitro organ bath studies of detrusor muscle strips were performed. Results: In vivo cystometry revealed that the rats in the CBI group had a significantly higher micturition frequency, lower bladder capacity, and lower compliance than the rats in the control and CBI+ mirodenafil groups. The detrusor muscle strip study showed that the magnitude of the carbachol-induced contractile response was significantly lower in the CBI group compared to either the control or CBI + mirodenafil group. Addition of daily mirodenafil after induction of CBI decreased the contractile response, compared to untreated CBI rats. CBI induced submucosal fibrosis and degenerative changes in bladder walls, which was reversed by the addition of mirodenafil.

Conclusions: Daily treatment with mirodenafil showed protective effects against bladder dysfunction resulting from CBI in rats.

Keywords: Ischemia; Urinary Bladder; Phosphodiesterase 5 Inhibitors

- Grant Support: This study was supported by a National Research Foundation of Korea (NRF) grant funded by the Korea Government (MSIP) (No. 2011-0020128).

- Research Ethics: This study was performed in accordance with the animal experiment protocols of the Korea University Ansan Hospital Animal Laboratory, after being approved by the Institutional Animal Care and Use Committee (KUIACUC-2013-117).

- Conflict of Interest: No potential conflict of interest relevant to this article was reported.

\section{INTRODUCTION}

Aging is associated with decreased bladder capacity, increased uninhibited contractions, decreased urinary flow rate, diminished urethral pressure profile, and increased postvoid residual urine volume [1,2].

Benign prostatic hyperplasia $(\mathrm{BPH})$ is typically the main presumptive cause in men with lower urinary tract symptoms (LUTS), but about one-third to more than half of men with LUTS do not show bladder outlet obstruction [3]. In other

Corresponding author: Jeong Gu Lee (iD http://orcid.org/0000-0002-0467-4913 Department of Urology, Korea University Anam Hospital, Korea University College of Medicine, 73 Inchon-ro, Seongbuk-gu, Seoul 136-705, Korea E-mail: doc71377@gmail.com / Tel: +82-2-920-5683 / Fax: +82-2-928-7864 Submitted: February 4, 2015 / Accepted after revision: March 5, 2015 
words, multiple factors are involved in the pathophysiological mechanisms of LUTS development.

LUTS and erectile dysfunction (ED) are medical conditions that can have a negative impact on quality of life, and usually coexist in aging men [4,5]. Epidemiological studies have found high comorbidity rates and associations between LUTS and ED, suggesting a pathophysiological link between these two medical conditions.

There have been few etiological studies on the association between vasculogenic risk factors and LUTS, and the effects of cardiovascular changes on detrusor function remain unclear. Pathological changes, such as smooth muscle alteration and denervation in several urologic organs, including the prostate, penis, and urinary bladder tissue, are generally ascribed to pelvic ischemia or atherosclerosis [6].

In humans and some animal models, the nitric oxide-cyclic guanosine monophosphate (NO-cGMP) pathway and phosphodiesterase-5 (PDE-5) expression have been detected in bladder tissue $[7,8]$. Chronic ischemic conditions may thus affect bladder cGMP levels, and could eventually influence smooth muscle and voiding function. Several studies have reported a clinical effect of PDE-5 inhibitors on the improvement of LUTS, in addition to erectile function $[9,10]$. A convenient rat model of chronic bladder ischemia (CBI), induced by balloon-catheter vascular endothelial injury in addition to a high-cholesterol diet, is available for such urological studies $[11,12]$.

Mirodenafil is the most recently developed PDE- 5 inhibitor and has proven clinical efficacy in ED, similar to other PDE-5 inhibitors. Experimental studies have revealed that the selectivity of mirodenafil for PDE-5 is ten-folds higher than that of sildenafil, while its inhibitory effects on other PDEs are much lower than those of sildenafil [13]. Despite its relatively short pharmacological half-life, the clinical effects of mirodenafilare maintained for at least 12 hours.

In this study, we investigated the protective effects of mirodenafil on bladder dysfunction in a rat model of CBI using urodynamics, detrusor muscle strips, and histological examination.

\section{MATERIALS AND METHODS}

\section{Animal Model Design With Surgical Induction of CBI}

Our study was performed in accordance with the animal experiment protocols of the Korea University Ansan Hospital Animal Laboratory, after being approved by the Institutional Animal Care and Use Committee (KUIACUC-2013-117). Adult male Sprague-Dawley rats weighing 450-500 g at 16 weeks were randomized to control, $\mathrm{CBI}$, and $\mathrm{CBI}+$ mirodenafil groups.

Rats were housed two per cage in a room maintained at $22^{\circ} \mathrm{C}-24^{\circ} \mathrm{C}$ with an alternating 12 -hour light/dark cycle (the lights came on automatically at $7 \mathrm{AM}$ ). Rats were given ad libitum access to food and water.

The control group underwent sham surgery and was fed standard food for eight weeks. The CBI and CBI + mirodenafil groups underwent surgery to induce aortoiliac atherosclerosis, as previously described $[11,12]$.

Briefly, rats were anesthetized with isoflurane (1.5\%-2.5\%), and a bilateral inguinal incision was used to expose the bifurcation site of the femoral and superficial epigastric arteries. A Fogarty arterial embolectomy catheter (E-060 2F, EdwardsLife sciences, Irvine, CA, USA) was passed through the right and left femoral arteriotomies to just above the aortic bifurcation. The balloon was inflated with air and subsequently withdrawn from the common iliacartery to the femoral artery. The maneuver was repeated ten times on each side. Sham operations were carried out in the control group untilthe vessel exposure step after the inguinal incision.

The CBI and CBI + mirodenafil groups received a $2 \%$ cholesterol diet (Research Diets, New Brunswick, NJ, USA) for eight weeks. Four weeks postoperatively, the CBI + mirodenafil group started daily mirodenafil at $4-\mathrm{mg} / \mathrm{kg}$ body weight. Two solutions of mirodenafil were prepared in purified drinking water, and $0.3-0.5 \mathrm{~mL}$ of each solution was administered with an oral Zonde needle. Mirodenafil was administered orally for four weeks until the day of cystometry.

\section{Urodynamics and Organ Bath Study}

Rats were anesthetized with isoflurane (1.5\%-2.5\%), and a low midline incision was made. The bladder was exposed, and a PE-10 polyethylene catheter (Clay-Adams, Parsippany, NJ, USA) was inserted into the bladder through a small 1-mm incision and anchored with sutures.

A three-way connector was used; one side of the catheter was connected to a Harvard infusion pump to instill normal saline into the bladder, and the other side was connected to a polygraph (Grass Medical Instruments, Quincy, MA, USA) through the pressure transducer to measure intravesicular pressure.

After a 30-minute equilibration period, room temperature normal saline was infused into the bladder at $0.04 \mathrm{~mL} / \mathrm{min}$ by infusion pump. The reproducible voiding cycles were recorded for 30-120 minutes. Baseline pressure (BP), threshold pressure 
(TP), maximum pressure (MP), and micturition frequency (MF) were measured by cystometry, and the mean values were determined. Bladder capacity (Bcap [infusion rate/MF]) and bladder compliance (Bcom [Bcap/TP-BP]) were calculated using the respective formulas.

The bladder was subsequently removed and weighed. The lower two-thirds of the bladder were placed in a plate filled with Krebs-Henseleit solution saturated with $95 \%$ oxygen and 5\% carbon dioxide.

The bladder body was cut longitudinally into $2 \times 2 \times 6-\mathrm{mm}$ bladder strips and placed in 10-mL organ bath chambers. The chambers were filled with Krebs-Henseleit solution maintained at $37^{\circ} \mathrm{C}$, and $95 \%$ oxygen was continuously bubbled through them.

The strips were suspended between two L-shaped hooksby 4-0 silk ligatures. One side of the hook was then connected to the bath, and the other was connected to an FT03C force transducer (Grass Instruments, Rockland, MA, USA). The strips were stretched with $2-\mathrm{g}$ passive tension and allowed to equilibrate for 30 minutes before further experiments. Carbachol concentration-response curves were generated by adding increasing concentrations of carbachol at log increments from $10^{-6}$ to $10^{-3} \mathrm{~mol} / \mathrm{L}$. Contractile force was calculated based on the weight of the strip.

\section{Histological Examination and Statistics}

We analyzed the histology of the bladder and blood vessels that had been removed from the abdominal aorta to the common iliac artery. Specimens were fixed in phosphate-buffered $10 \%$ formaldehyde solution and embedded in paraffin. Hematoxylin and eosin staining was used to observe structural abnormalities, such as degenerative changes and fibrosis in blood vessels.
Masson trichrome staining of bladder tissues was used to determine the collagen content as a percentage of the bladder muscle layer. Four high power fields were randomly selected for each specimen, and the percentage collagen in the bladder muscle layer was calculated as the sum of the blue-stained areas divided by the sum of all red-and blue-stained areas, using Image-Pro Express image analysis software (Media Cybernetics, Silver Spring, Rockville, MD, USA). Data were processed using SPSS ver.12 (SPSS Inc., Chicago, IL, USA). Comparisons between groups were carried out by one-way analysis of variance, followed by the Bonferroni post hoc test with $\mathrm{P}<0.05$ considered statistically significant.

\section{RESULTS}

No rats died during the CBI model production or sham operation process. In addition, there were no postoperative side effects or remarkable problems associated with oral feeding of mirodenafil. No significant differences were observed between the control, $\mathrm{CBI}$, and $\mathrm{CBI}+$ mirodenafil groups in bodyweight or bladder weight; the bodyweights were $523.6 \pm 40.2 \mathrm{~g}$ (control),

Table 1. Differences in bodyweight and bladder weight between control, CBI, and CBI + mirodenafil groups

\begin{tabular}{lcc}
\hline Group & Body weight $(\mathrm{g})$ & Bladder weight $(\mathrm{g})$ \\
\hline Control $(\mathrm{n}=8)$ & $523.6 \pm 40.2$ & $0.15 \pm 0.003$ \\
CBI $(\mathrm{n}=8)$ & $545.3 \pm 32.3$ & $0.18 \pm 0.005$ \\
CBI + mirodenafil $(\mathrm{n}=8)$ & $535.5 \pm 29.3$ & $0.19 \pm 0.005$ \\
\hline
\end{tabular}

Values are presented as the mean \pm standard deviation. $\mathrm{CBI}$, chronic bladder ischemia.

Table 2. Results of cystometric parameters, showing a decrease in ICI, Bcap, and Bcom in the CBI group

\begin{tabular}{lccc}
\hline Parameter & Control $(\mathrm{n}=8)$ & CBI $(\mathrm{n}=8)$ & CBI + mirodenafil $(\mathrm{n}=8)$ \\
\hline BP $(\mathrm{mmHg})$ & $3.4 \pm 0.8$ & $3.6 \pm 0.5$ & $3.3 \pm 0.3$ \\
TP (mmHg) & $10.8 \pm 1.5$ & $11.8 \pm 0.6$ & $10.9 \pm 0.8$ \\
MP (mmHg) & $28.2 \pm 2.5$ & $27.2 \pm 0.4$ & $29.2 \pm 1.0$ \\
TP-BP (mmHg) & $7.4 \pm 1.3$ & $8.2 \pm 0.9$ & $7.6 \pm 0.5$ \\
ICI (min) & $5.3 \pm 1.2^{\mathrm{a}}$ & $2.1 \pm 0.5$ & $\left.4.2 \pm 1.0^{\mathrm{b}}\right)$ \\
Bcap (mL) & $1.1 \pm 0.06^{\mathrm{a})}$ & $0.4 \pm 0.03$ & $0.9 \pm 0.04^{\mathrm{b})}$ \\
Bcom (mL/mmHg) & $0.15 \pm 0.02^{\mathrm{a}}$ & $0.05 \pm 0.04$ & $0.12 \pm 0.03^{\mathrm{b})}$ \\
\hline
\end{tabular}

Values are presented as the mean \pm standard deviation.

ICI, intercontraction interval; Bcap, bladder capacity (infusion rate/micturition frequency); Bcom, bladder compliance (Bcap/[TP-BP]); CBI, chronic bladder ischemia; $\mathrm{BP}$, baseline pressure; TP, threshold pressure; MP, maximum pressure.

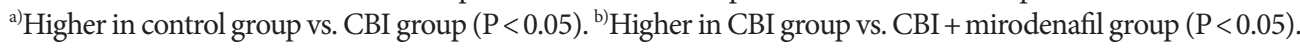


$545.3 \pm 32.3 \mathrm{~g}(\mathrm{CBI})$, and $535.5 \pm 29.3 \mathrm{~g}(\mathrm{CBI}+$ mirodenafil), and the corresponding bladder weights were $0.15 \pm 0.003 \mathrm{~g}, 0.18 \pm$ $0.005 \mathrm{~g}$, and $0.19 \pm 0.005 \mathrm{~g}$ (Table 1 ).

\section{Urodynamics and Organ Bath Study}

Cystometric results are shown in Table 2 and Fig. 1. The intercontraction interval was significantly decreased in the CBI group ( $2.1 \pm 0.5$ minutes) compared to the control (5.3 \pm 1.2 minutes) and $\mathrm{CBI}+$ mirodenafil groups (4.2 \pm 1.0 minutes). The CBI group also had significantly lower Bcap $(0.4 \pm 0.03$ vs. $1.1 \pm$ $0.06 / 0.9 \pm 0.04 \mathrm{~mL})$ and Bcom $(0.05 \pm 0.04$ vs. $0.15 \pm 0.02 /$ $0.12 \pm 0.03 \mathrm{~mL} / \mathrm{mmHg}$ ) values compared to the control/CBI + mirodenafil groups. No differences were observed between the control and CBI+mirodenafil groups. However, BP, TP, and MP did not differ significantly among the three groups.

Changes in the overall contractile response in bladder strips are shown in Fig. 2. As the carbachol dose was increased from $10^{-6}$ to $10^{-3} \mathrm{~mol} / \mathrm{L}$, the control and $\mathrm{CBI}+$ mirodenafil groups showed a normal dose-dependent contraction curve compared to a definite decrease in contractile force in the CBI group. A significant difference was noted at a carbachol dose of $10^{-5}$ to $10^{-}$ ${ }^{3} \mathrm{~mol} / \mathrm{L}$, but there was no difference in contractile response in the control and CBI + mirodenafil groups, confirming that mirodenafil significantly reduced the loss of contractile force caused by CBI.

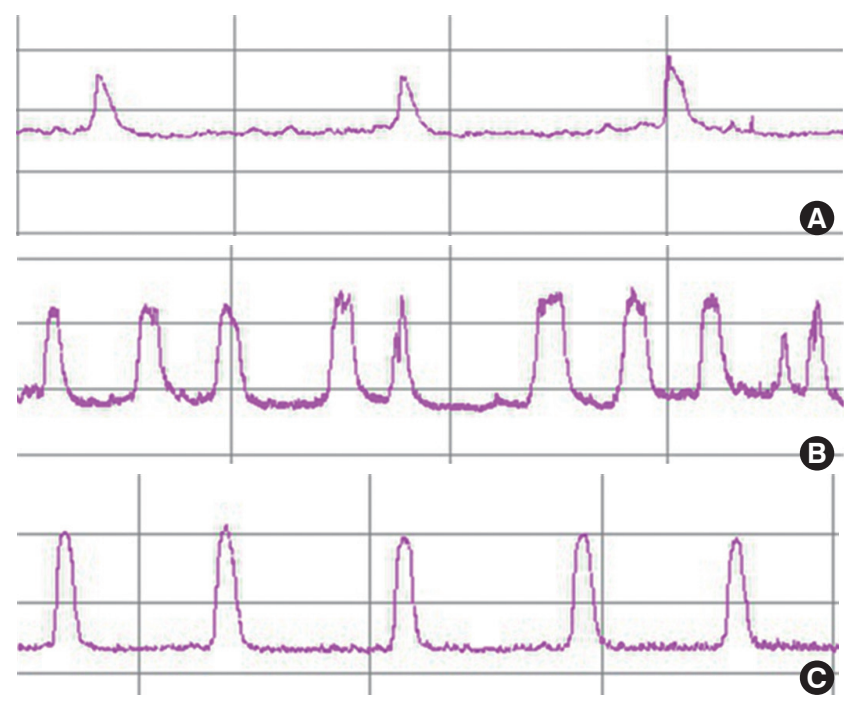

Fig. 1. Representative cystometric curves in each group. Intercontraction interval was significantly shorter in chronic bladder ischemia (CBI) rats than in the other groups. (A) Control group, (B) $\mathrm{CBI}$ group, and $(\mathrm{C}) \mathrm{CBI}+$ mirodenafil group.

\section{Histological Examination}

Hematoxylin and eosin staining of the common iliac arteries from the CBI + mirodenafil group demonstrated moderate submucosal fibrosis, which was different from histological observations in the control group. However, fibrosis was more common and severe in the CBI group compared to the $\mathrm{CBI}+$ mirodenafil group. Thickening of the tunica intima as well as degenerative changes in the tunica media were found in the $\mathrm{CBI}$ and $\mathrm{CBI}+$ mirodenafil groups, whereas no pathologic changes were observed in the control group. The changes were also more severe in the CBI group than in the CBI + mirodenafil group. Masson trichrome staining of bladder tissue revealed a significantly increased percentage of collagen in the muscle layer in the CBI group $(36.1 \% \pm 1.7 \%)$ compared with the control $(22.3 \% \pm 1.8 \%)$ and CBI + mirodenafil groups $(25.9 \% \pm 1.6 \%)$ (Figs. 3,4$)$.

\section{DISCUSSION}

Our study confirmed that mirodenafil had protective effects on bladder function and morphology, eventually resulting in decreased bladder hyperactivity in an induced arterial occlusive CBI model. This effect is consistent with the observation of PDE-5 expression and cGMP production in several lower uri-

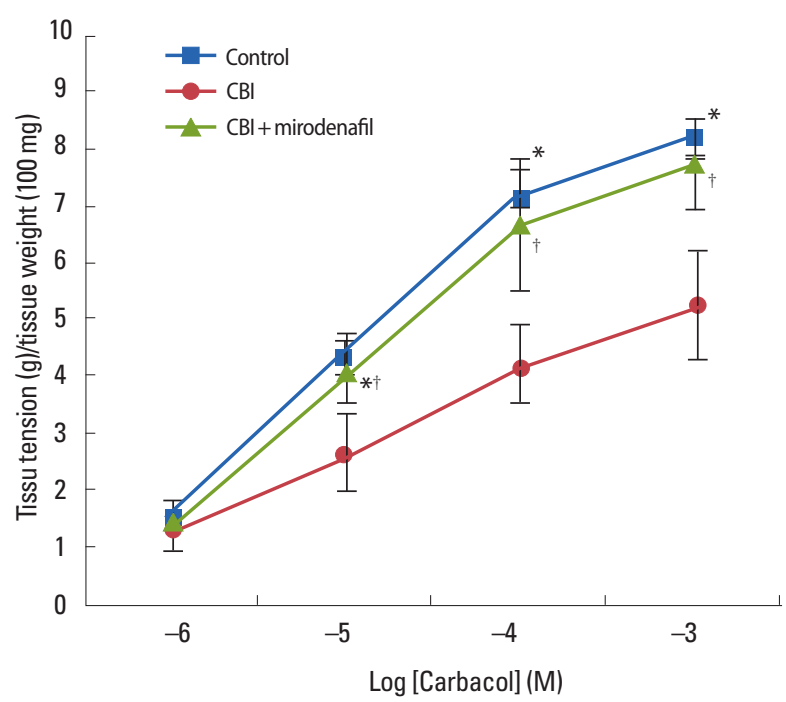

Fig. 2. Carbachol-induced contraction in the detrusor muscle strip from the control group, chronic bladder ischemia (CBI) group, and $\mathrm{CBI}+$ mirodenafil group. Contractile responses induced by carbacholin the CBI group were lower than in the control and $\mathrm{CBI}+$ mirodenafil groups $\left(10^{-6} \mathrm{~mol} / \mathrm{L}\right.$ to $\left.10^{-3} \mathrm{~mol} / \mathrm{L}\right)$. ${ }^{*}$ Higher in control group vs. CBI group $(\mathrm{P}<0.05) .{ }^{\dagger}$ Higher in $\mathrm{CBI}$ group vs. $\mathrm{CBI}+$ mirodenafil group $(\mathrm{P}<0.05)$. 

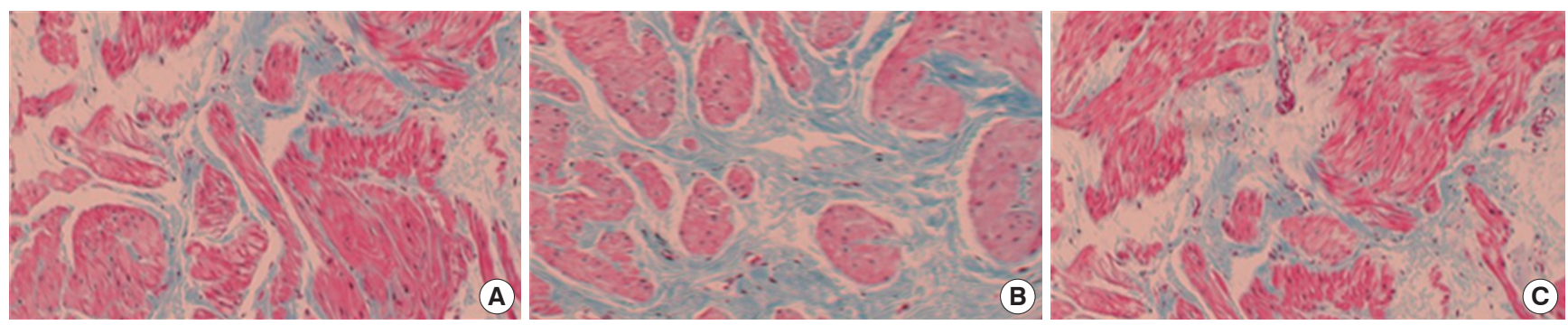

Fig. 3. Bladder tissue of control group (A), chronic bladder ischemia (CBI) group (B), and CBI + mirodenafil group (C) (Masson trichrome stain, $\times 100)$.

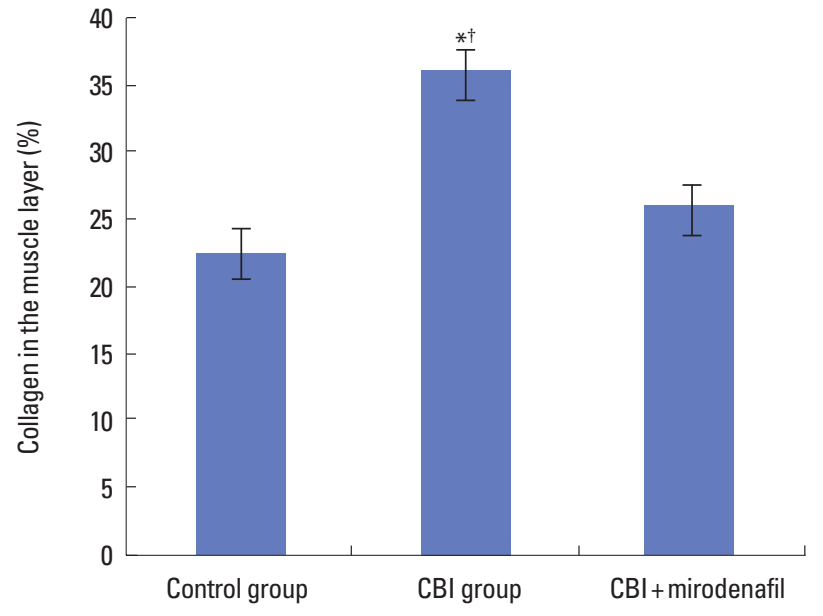

Fig. 4. Percentage of collagen in the muscle layer in control, chronic bladder ischemia (CBI), and CBI + mirodenafil groups. ${ }^{*}$ Higher in control group vs. CBI group $(\mathrm{P}<0.05) .{ }^{\dagger}$ Higher in CBI group vs. CBI + mirodenafil group $(\mathrm{P}<0.05)$.

nary tract structures in urologic organs under hypoxic conditions in previous animal studies [14,15].

It is well-established that LUTS increase in frequency with aging. Age-related alterations in bladder function require differentiation between symptoms associated with aging and those related to comorbid conditions [16-18].

Current reports on community-based and clinical data show a consistent association between LUTS and ED, and there are some correlations based on the similarities in pathophysiology $[19,20]$. For instance, decreased NO synthase/NO levels, pathways involve RhoA-Rho-kinase activation and pelvic atherosclerosis as an underlying etiology of LUTS and ED [21,22].

Among other reasons, vasculogenic dysfunction is an independent risk factor for atherosclerosis and increases with aging. Bifurcation of the iliac arteries makes them especially vulnerable to atherosclerotic lesions, and atherosclerotic disruptive changes distal to the aortic bifurcation may influence the distal vasculature. Such defects in vascular supply to the urologic organs, including the bladder, may explain voiding dysfunction observed in the elderly, including detrusor fibrosis and impaired contractility, collagen deposition, and loss of acetylcholinesterase-positive nerve terminals [23-25].

Collagen deposition and fibrosis are recognized phenomena in aging bladders, and can be explained by gradual loss of compliance and bladder capacity with age. With regard to deterioration of detrusor muscle function and the loss of cholinergic innervation, there is some evidence for muscarinic denervation in the aging bladder. The relevance of pathologic findings to clinical dysfunction remains unclear [26,27].

We note that the acute ischemia model has limitations since it is difficult to extrapolate to a clinical setting. There is also a rabbit CBI model associated with atherosclerosis $[18,28]$. The CBI model has been significantly advanced by Nomiya et al. [11], who developed it in rats. Experimental applications, such as urodynamics, have been much easier in this rat model. Several studies have shown that the arterial injury procedure in this model may affect the damaged sites of balloon injury $[28,29]$.

CBI model-based data suggest that Eviprostat might be an attractive treatment option for individuals with bladder dysfunction because of its antioxidant and anti-inflammatory properties [30]. Administering the lipid soluble provitamin Coenzyme Q10 as a scavenger for free radicals also decreased the frequency of micturition, and increased Bcap and detrusor contractility [12].

In this study, we used the current rat model to confirm previous observations that iliac arteries from the CBI group show significantly increased arterial wall thickness compared with the other groups. Furthermore, we found that rats with CBI showed an increase in MF, a decrease in Bcap and Bcom, and decreased contractile responses to carbachol, compared with control and mirodenafil-treated rats.

We chose a daily oral mirodenafil dose of $4 \mathrm{mg} / \mathrm{kg}$, based on a dose used previously [31]. There was no difference between the 
control and CBI + mirodenafil groups, implying that treatment with mirodenafil prevented the decrease in bladder impairment due to chronic ischemia. This result is in agreement with previous data on tadalafil, a different type of PDE-5 inhibitor [32].

Atherosclerosis shows marked inflammatory progression, with numerous inflammatory cytokines and a high level of oxidative stress, and lipid and protein oxidation in the vascular wall [17]. PDE-5 inhibitors partially reverse the contraction of prostatic tissue and increase cGMP levels, resulting in antiproliferative effects on prostatic smooth muscle cells [20]. PDE-5 inhibitors control bladder muscle tone by activating NO-cGMP signaling, and inhibit the micturition reflex by affecting sensory pathways in the bladder. PDE-5 inhibitors also reduce cGMPdependent RhoA-Rho-kinase signaling, which influences storage LUTS [21]. In addition, chronic use of PDE-5 inhibitors has an anti-inflammatory effect on endothelial cells [33]. Thus, increased arterial blood flow to the bladder neck and prostate may be the mechanism underlying the efficacy of PDE-5 inhibitors in treating LUTS [22].

Our results indicated that mirodenafil administration significantly decreased the percentage of collagen in the muscle layer, and improved the decreased contractile response to cholinergic stimulation, compared to the CBI group. We also observed a significant improvement in urodynamic parameters.

PDE-5 inhibitors, such as vardenafil, have proven valuable in improving LUTS in several clinical studies. A single 20-mg dose of vardenafil led to a significant decrease in maximum detrusor pressure, an improvement in maximum bladder volume, and a significant increase in detrusor overactivity volume in spinal cord injury patients [34,35].

Mirodenafil (Mvix, SK Chemicals, Seoul, Korea) is the most recently developed PDE-5 inhibitor, and is a novel, potent agent with clinical efficacy in ED similar to that of other PDE-5 inhibitors. An animal study showed that the selectivity of mirodenafil was ten times higher than that of sildenafil, and its inhibitory effects on other PDE-5 inhibitors were very small. The high selectivity of mirodenafil may have contributed to the favorable results obtained in our study, despite its disadvantageous kinetics.

Despite their advantages, PDE-5 inhibitors are not typically used as monotherapies. Alpha-blocker monotherapy is widely accepted as the initial medical treatment for patients with $\mathrm{BPH}$ LUTS, especially for relatively younger patients with mild symptoms. Most urologists prefer monotherapy, considering the rapid onset, efficacy, and avoidance of possible adverse events associated with polypharmacy, because most elderly pa- tients take several medications [6].

Although combination therapy using $5 a$-reductase inhibitors or anticholinergics has proven effective for the treatment of complex BPH-LUTS, these therapies may have undesirable side effects [3,7]. Urologists face limited choices when treating patients with severe BPH-LUTS, especially elderly patients who require high efficacy with minimal drug interactions. The results of our study suggest a single-treatment option for patients.

Although the establishment of a concrete rationale for continuous treatment of BPH-LUTS and ED patients with PDE-5 inhibitors faces many obstacles, daily mirodenafil suggests the possibility of advancement in the medical treatment of agingassociated LUTS.

Limitations of our study include the lack of concentration measurements in serum or tissue, and dose escalation of mirodenafil. PDE-5 inhibitors as the principal hypothesis in the reduction of $\mathrm{NO}$ is only one of several possible experimental efforts, so definite conclusive results cannot be obtained. Moreover, data on some important parameters, such as systemic blood pressure and variable nonvoiding contractions, are lacking. Previous studies on mirodenafil were inadequate, and further comprehensive evaluation is required.

Considering the additive effects of PDE- 5 inhibitors for improving bladder overactivity, mirodenafil could be useful for combination treatment of patients with refractory LUTS who do not respond to monotherapy, for patients who need polypharmacy for combined disease, or as a continuous alternative treatment for improving detrusor overactivity. With chronic use of mirodenafil in elderly patients, synergism and antagonism with frequently used drugs should be taken into consideration. Human studies are necessary to confirm the benefits of mirodenafil.

In conclusion, this study confirmed that balloon-induced CBI leads to changes in bladderwall morphology/contractility and showed that mirodenafil ameliorated bladder dysfunction induced by atherosclerosis. Mirodenafil may have protective effects on bladder function and morphology, and may result in decreased bladder hyperactivity. Thus, mirodenafil may be useful in the clinical treatment of bladder dysfunction due to CBI.

\section{REFERENCES}

1. Diokno AC, Brown MB, Goldstein N, Herzog AR. Epidemiology of bladder emptying symptoms in elderly men. J Urol 1992;148:181721. 
2. Madersbacher S, Pycha A, Schatzl G, Mian C, Klingler CH, Marberger $\mathrm{M}$. The aging lower urinary tract: a comparative urodynamic study of men and women. Urology 1998;51:206-12.

3. Yamaguchi O, Aikawa K, Shishido K, Nomiya M. Place of overactive bladder in male lower urinary tract symptoms. World J Urol 2009;27:723-8.

4. Hoesl CE, Woll EM, Burkart M, Altwein JE. Erectile dysfunction (ED) is prevalent, bothersome and underdiagnosed in patients consulting urologists for benign prostatic syndrome (BPS). Eur Urol 2005;47:511-7.

5. Rosen R, Altwein J, Boyle P, Kirby RS, Lukacs B, Meuleman E, et al. Lower urinary tract symptoms and male sexual dysfunction: the multinational survey of the aging male (MSAM-7). Eur Urol 2003;44: 637-49.

6. Andersson KE, de Groat WC, McVary KT, Lue TF, Maggi M, Roehrborn CG, et al. Tadalafil for the treatment of lower urinary tract symptoms secondary to benign prostatic hyperplasia: pathophysiology and mechanism(s) of action. Neurourol Urodyn 2011;30: 292-301.

7. Werkstrom V, Hedlund P, Lee T, Andersson KE. Vardenafil-induced relaxation and cyclic nucleotide levels in normal and obstructed rat urinary bladder. BJU Int 2009;104:1740-5.

8. Bittencourt JA, Tano T, Gajar SA, Resende AC, de Lemos Neto M, Damiao R, et al. Relaxant effects of sildenafil on the human isolated bladder neck. Urology 2009;73:427-30.

9. Egerdie RB, Auerbach S, Roehrborn CG, Costa P, Garza MS, Esler $\mathrm{AL}$, et al. Tadalafil 2.5 or $5 \mathrm{mg}$ administered once daily for 12 weeks in men with both erectile dysfunction and signs and symptoms of benign prostatic hyperplasia: results of a randomized, placebocontrolled, double-blind study. J Sex Med 2012;9:271-81.

10. Tamimi NA, Mincik I, Haughie S, Lamb J, Crossland A, Ellis P. A placebo-controlled study investigating the efficacy and safety of the phosphodiesterase type 5 inhibitor UK-369,003 for the treatment of men with lower urinary tract symptoms associated with clinical benign prostatic hyperplasia. BJU Int 2010;106:674-80.

11. Nomiya M, Yamaguchi O, Andersson KE, Sagawa K, Aikawa K, Shishido K, et al. The effect of atherosclerosis-induced chronic bladder ischemia on bladder function in the rat. Neurourol Urodyn 2012;31:195-200.

12. Kim JW, Jang HA, Bae JH, Lee JG. Effects of coenzyme Q10 on bladder dysfunction induced by chronic bladder ischemia in a rat model. J Urol 2013;189:2371-6.

13 Paick JS, Ahn TY, Choi HK, Chung WS, Kim JJ, Kim SC, et al. Efficacy and safety of mirodenafil, a new oral phosphodiesterase type 5 inhibitor, for treatment of erectile dysfunction. J Sex Med 2008;5:
2672-80.

14. Lin G, Xin ZC, Lue TF, Lin CS. Up and down-regulation of phosphodiesterase- 5 as related to tachyphylaxis and priapism. J Urol 2003;170(2 Pt 2):S15-8.

15. Azadzoi KM, Babayan RK, Kozlowski R, Siroky MB. Chronic ischemia increases prostatic smooth muscle contraction in the rabbit. J Urol 2003;170(2 Pt 1):659-63.

16. Ameda K, Sullivan MP, Bae RJ, Yalla SV. Urodynamic characterization of nonobstructive voiding dysfunction in symptomatic elderly men. J Urol 1999;162:142-6.

17. Pagala MK, Tetsoti L, Nagpal D, Wise GJ. Aging effects on contractility of longitudinal and circular detrusor and trigone of rat bladder. J Urol 2001;166:721-7.

18. Azadzoi KM, Tarcan T, Kozlowski R, Krane RJ, Siroky MB. Overactivity and structural changes in the chronically ischemic bladder. J Urol 1999;162:1768-78.

19. Gacci M, Eardley I, Giuliano F, Hatzichristou D, Kaplan SA, Maggi $\mathrm{M}$, et al. Critical analysis of the relationship between sexual dysfunctions and lower urinary tract symptoms due to benign prostatic hyperplasia. Eur Urol 2011;60:809-25.

20. McVary KT. Erectile dysfunction and lower urinary tract symptoms secondary to BPH. Eur Urol 2005;47:838-45.

21. Morelli A, Chavalmane AK, Filippi S, Fibbi B, Silvestrini E, Sarchielli E, et al. Atorvastatin ameliorates sildenafil-induced penile erections in experimental diabetes by inhibiting diabetes-induced RhoA/Rho-kinase signaling hyperactivation. J Sex Med 2009;6:91106.

22. Bertolotto M, Trincia E, Zappetti R, Bernich R, Savoca G, Cova MA. Effect of Tadalafil on prostate haemodynamics: preliminary evaluation with contrast-enhanced US. Radiol Med 2009;114:1106-14.

23. Lepor H, Sunaryadi I, Hartanto V, Shapiro E. Quantitative morphometry of the adult human bladder. J Urol 1992;148(2 Pt 1):414-7.

24. Hald T, Horn T. The human urinary bladder in ageing. Br J Urol 1998;82 Suppl 1:59-64.

25. Gosling JA. Modification of bladder structure in response to outflow obstruction and ageing. Eur Urol 1997;32 Suppl 1:9-14.

26. Ameda K, Koyanagi T, Nantani M, Taniguchi K, Matsuno T. The relevance of preoperative cystometrography in patients with benign prostatic hyperplasia: correlating the findings with clinical features and outcome after prostatectomy. J Urol 1994;152(2 Pt 1):443-7.

27. Lluel P, Palea S, Barras M, Grandadam F, Heudes D, Bruneval P, et al. Functional and morphological modifications of the urinary bladder in aging female rats. Am J Physiol Regul Integr Comp Physiol 2000;278:R964-72.

28. Azadzoi KM, Tarcan T, Siroky MB, Krane RJ. Atherosclerosis-in- 
duced chronic ischemia causes bladder fibrosis and non-compliance in the rabbit. J Urol 1999;161:1626-35.

29. Saitoh S, Onogi F, Aikawa K, Muto M, Saito T, Maehara K, et al. Multiple endothelial injury in epicardial coronary artery induces downstream microvascular spasm as well as remodeling partly via thromboxane A2. J Am Coll Cardiol 2001;37:308-15.

30. Matsui T, Oka M, Fukui T, Tanaka M, Oyama T, Sagawa K, et al. Suppression of bladder overactivity and oxidative stress by the phytotherapeutic agent, Eviprostat, in a rat model of atherosclerosisinduced chronic bladder ischemia. Int J Urol 2012;19:669-75.

31. Kang JY, Kim EK, Kim KM. Effects of mirodenafil, a phosphodiesterase-5 inhibitor, on female rat bladder in a partial bladder outlet obstruction model: physiological and immunohistochemical aspects. Korean J Urol 2013;54:339-44.

32. Nomiya M, Burmeister DM, Sawada N, Campeau L, Zarifpour M, Keys T, et al. Prophylactic effect of tadalafil on bladder function in a rat model of chronic bladder ischemia. J Urol 2013;189:754-61.

33. Roumeguere T, Zouaoui Boudjeltia K, Babar S, Nuyens V, Rousseau A, Van Antwerpen P, et al. Effects of phosphodiesterase inhibitors on the inflammatory response of endothelial cells stimulated by myeloperoxidase-modified low-density lipoprotein or tumor necrosis factor alpha. Eur Urol 2010;57:522-8.

34. Gacci M, Del Popolo G, Macchiarella A, Celso M, Vittori G, Lapini A, et al. Vardenafil improves urodynamic parameters in men with spinal cord injury: results from a single dose, pilot study. J Urol 2007;178:2040-3.

35. Tamimi NA, Mincik I, Haughie S, Lamb J, Crossland A, Ellis P. A placebo-controlled study investigating the efficacy and safety of the phosphodiesterase type 5 inhibitor UK-369,003 for the treatment of men with lower urinary tract symptoms associated with clinical benign prostatic hyperplasia. BJU Int 2010;106:674-80. 